\section{THU0211 META-ANALYSIS OF SERIOUS INFECTIONS WITH BARICITINIB, TOFACITINIB AND BIOLOGIC DMARDS IN RHEUMATOID ARTHRITIS}

V. Strand ${ }^{1}$, S. Ahadieh ${ }^{2}$, R. DeMasi ${ }^{3}$, S. Krishnaswami ${ }^{2}$, J. Geier ${ }^{4}$, S. Menon ${ }^{2}$, J.J. Gomez-Reino ${ }^{5}$. ${ }^{1}$ Division of Immunology/ Rheumatology, Standford University, Palo Alto, CA; ${ }^{2}$ Pfizer Inc, Groton, CT; ${ }^{3}$ Pfizer Inc, Collegeville, PA; ${ }^{4}$ Pfizer Inc, New York, NY, United States; ${ }^{5}$ Fundacion Ramon Dominguez, Hospital Clinico Universitario, Santiago de Compostela, Spain

Background: Tofacitinib is an oral Janus kinase (JAK) inhibitor for the treatment of rheumatoid arthritis (RA). Baricitinib is a JAK inhibitor being investigated for RA. Serious infection events (SIEs) have been reported in RA randomised controlled trials (RCTs) but limited head-to-head data are available to directly compare rates of these events for tofacitinib vs biologic (b)DMARDs and baricitinib.

Objectives: We present an updated meta-analysis of published RCTs and corresponding long-term extension (LTE) studies to contextualise the risk of SIEs with tofacitinib and extend this work to include the JAK inhibitor baricitinib.

Methods: An initial systematic literature search (Medline, Embase, PubMed and regulatory submission documents) was conducted for SIEs with tofacitinib and bDMARDs (abatacept, adalimumab, certolizumab, etanercept, golimumab, infliximab, rituximab and tocilizumab). ${ }^{1}$ A subsequent systematic literature review of RCTs was conducted using Medline, BIOSIS, Embase and conference abstracts to evaluate SIEs with baricitinib. Incidence rates (IRs; patients with events per 100 patient-years) were calculated for each agent, utilising a random effects meta-analytic model using R (version 2.15.2 for tofacitinib and bDMARDs; version 3.2.2 for baricitinib) with a Restricted Maximum Likelihood Estimator for between-study variances. Risk ratios and risk differences were calculated for each agent vs control across RCTs up to rescue of patients randomised to receive placebo using the random effects Mantel-Haenszel method.

Results: Six RCTs with baricitinib were included in this updated analysis. In the original analysis, 70 RCTs and 18 LTE studies met inclusion criteria for tofacitinib and bDMARDs. The table provides a summary of the meta-analyses conducted for SIE IRs (with and without LTE), risk ratios and risk differences relative to control. The IRs $\left(95 \%\right.$ confidence interval $[\mathrm{Cl}]$; heterogeneity $\left.\left[\mathrm{I}^{2}\right]\right)$ for baricitinib were $4.75\left(2.32,9.74 ; I^{2}=19 \%\right)$ for $2 \mathrm{mg}$ and $3.67\left(2.33,5.78 ; \mathrm{I}^{2}=36 \%\right)$ for 4 $\mathrm{mg}$. The analysis of risk ratios ( $\mathrm{p}$ values 0.22 for $2 \mathrm{mg}$; 0.95 for $4 \mathrm{mg}$ ) and risk differences ( $p$ values 0.41 for $2 \mathrm{mg} ; 1.00$ for $4 \mathrm{mg}$ ) did not reveal a significant difference from control for both doses of baricitinib, which is consistent with analyses of tofacitinib and bDMARDs. There were limited data to assess SIE incidence for baricitinib $(4 \mathrm{mg})$ monotherapy vs in combination with methotrexate (MTX); the RA-BEGIN study showed IRs of $3.77(1.7,8.4)$ and $2.33(0.97,5.59)$, respectively. Pooled IR estimates for tofacitinib from the development programme were $1.70(0.91,2.92)$ and $1.79(1.00,2.95)$ for 5 and $10 \mathrm{mg}$ BID monotherapy, respectively; when administered in combination with MTX, the IRs were 3.44 $(2.41,4.76)$ and $3.42(2.42,4.70)$ for 5 and $10 \mathrm{mg} \mathrm{BID}$, respectively.

Table: Serious infection incidence rates, risk ratios and risk differences for tofacitinib vs biologic DMARDs and baricitinib ${ }^{1}$

\begin{tabular}{|c|c|c|c|c|}
\hline \multirow[t]{2}{*}{ Drug } & \multicolumn{2}{|c|}{$\begin{array}{c}\text { Incidence rate } \\
(95 \% \text { CI), per } 100 \text { pt-yr }\end{array}$} & \multirow{2}{*}{$\begin{array}{c}\text { Risk ratio } \\
(95 \% \text { CI) } \\
\text { RCT }\end{array}$} & \multirow{2}{*}{$\begin{array}{c}\text { Risk difference } \\
\text { (95\% CI), \% } \\
\text { RCT }\end{array}$} \\
\hline & $\mathrm{RCT}+\mathrm{LTE}$ & RCT & & \\
\hline Abatacept & $3.04(2.49,3.72)$ & $2.97(2.17,4.07)$ & $1.18(0.45,3.09)$ & $0.4(-0.72,1.51)$ \\
\hline Rituximab & $3.72(2.99,4.62)$ & $3.45(2.73,4.36)$ & $1.01(0.46,2.22)$ & $-0.42(-1.63,0.79)$ \\
\hline Tocilizumab & $5.45(4.26,6.96)$ & $5.39(4.05,7.18)$ & $1.82(1.22,2.73)$ & $1.51(0.68,2.33)$ \\
\hline Infliximab & $6.11(5.24,7.12)$ & $6.42(5.50,7.50)$ & $0.83(0.33,2.06)$ & $-0.52(-3.56,2.53)$ \\
\hline Etanercept & $4.06(3.26,5.08)$ & $3.90(2.76,5.52)$ & $1.00(0.07,15.24)$ & $0.00(-9.39,9.39)$ \\
\hline Certolizumab & $7.59(5.80,9.94)$ & $7.59(5.80,9.94)$ & $2.18(1.06,4.50)$ & $1.96(0.8,3.12)$ \\
\hline Golimumab & $5.31(4.09,6.89)$ & $5.31(4.09,6.89)$ & $1.3(0.43,3.90)$ & $0.68(-0.31,1.67)$ \\
\hline Adalimumab & $5.04(3.80,6.69)$ & $5.47(3.92,7.64)$ & $2.27(0.84,6.13)$ & $1.16(-0.34,2.67)$ \\
\hline TNF inhibitors & $4.90(4.41,5.44)$ & $5.50(4.86,6.23)$ & $1.50(1,2.25)$ & $0.94(0.25,1.63)$ \\
\hline Tofacitinib 5 mg, P2/P3 & $\mathrm{NA}$ & $\begin{array}{l}2.71(2.00,3.58)^{2} \\
2.35(1.36,4.06)^{b}\end{array}$ & $1.34(0.43,4.15)$ & $0.27(-0.36,0.9)$ \\
\hline Tofacitinib $10 \mathrm{mg}, \mathrm{P} 2 / \mathrm{P} 3$ & NA & $\begin{array}{l}2.72(2.04,3.56)^{\mathrm{a}} \\
2.80(1.95,4.01)^{\mathrm{b}}\end{array}$ & $1.67(0.60,4.65)$ & $0.42(-0.22,1.05)$ \\
\hline $\begin{array}{l}\text { Tofacitinib P123LTE } \\
\text { (All doses) }\end{array}$ & $2.74(2.51,2.99)^{2}$ & $\mathrm{NA}$ & NA & NA \\
\hline Baricitinib 2 mg & NA & $4.75(2.32,9.74)$ & $1.13(0.24,5.35)$ & $-0.35(-1.72,1.02)$ \\
\hline Baricitinib 4 mg & NA & $3.67(2.33,5.78)$ & $0.82(0.34,1.97)$ & $-0.21(-1.11,0.69)$ \\
\hline
\end{tabular}

a Estimate from pooled patient-level data

'Estimate from random effects meta-analytic model

CI, confidence interval; DMARDs, disease-modifying antirheumatic drugs; JAK, Janus kinase;

LTE, long-term extension; NA, not applicable; P2/P3, Phase 2 and Phase 3 studies; P123LTE, Phase 1, 2, 3 and LTE studies; pt-yr, patient year; RCT, randomised controlled trial; risk ratio, relative risk compared with placebo; risk difference, risk difference compared with placebo; TNF, tumour necrosis factor

Conclusions: The results from these meta-analyses suggest that the risk of SIEs (IRs, risk ratios and risk differences) with tofacitinib is comparable with published rates for bDMARDs and baricitinib in patients with moderate to severe RA.

References:

[1] Strand V et al. Arthritis Res Ther 2015; 17: 362.

Acknowledgements: This study was sponsored by Pfizer Inc. Editorial support was provided by $\mathrm{K}$ Nicholson and $\mathrm{C}$ Viegelmann of $\mathrm{CMC}$ and funded by Pfizer Inc.

Disclosure of Interest: V. Strand Consultant for: AbbVie, Amgen, Bristol-Myers Squibb, CORRONA, Eli Lilly, Janssen, Novartis, Pfizer Inc, UCB, S. Ahadieh Shareholder of: Pfizer Inc, Employee of: Pfizer Inc, R. DeMasi Shareholder of:
Pfizer Inc, Employee of: Pfizer Inc, S. Krishnaswami Shareholder of: Pfizer Inc, Employee of: Pfizer Inc, J. Geier Shareholder of: Pfizer Inc, Employee of: Pfizer Inc, S. Menon Shareholder of: Pfizer Inc, Employee of: Pfizer Inc, J. Gomez-Reino Grant/research support from: AbbVie, MSD, Novartis, Pfizer Inc, Roche, UCB, Speakers bureau: AbbVie, Biogen, Bristol-Myers Squibb, Janssen, MSD, Pfizer Inc, Roche, UCB

DOI: 10.1136/annrheumdis-2017-eular.2439

\section{THU0212 THE IMPROVEMENT OF ULTRASONOGRAPHIC FINDINGS FOR 24 WEEKS MAY PREDICT REMISSION AT 52 WEEKS IN JAPANESE RHEUMATOID ARTHRITIS PATIENTS TREATED WITH IGURATIMOD THERAPY}

Y. Kanayama $^{1}$, H. Nagasaka ${ }^{2}$, M. Shimotake ${ }^{2}$, F. Miyachi ${ }^{2}$, K. Fujita ${ }^{2}$, A. Nagata ${ }^{2}$. ${ }^{1}$ Orthopedic Surgery and Rheumatology; ${ }^{2}$ Clinical technology, Toyota Kosei Hospital, Toyota, Japan

Background: Iguratimod (IGU) suppressed tumor necrosis factor-alpha-induced production of interleukin (IL)-6, IL-8, and monocyte chemoattractant protein 1 via inhibition of nuclear factor kappa B activation in cultured human synovial cells and human acute monocytic leukemia cells. We reported the clinical efficacy of IGU at ACR2014 and EULAR2015. However there is still few studies of improvement of ultrasonographic findings in rheumatoid arthritis (RA) treated with IGU.

Objectives: To evaluate the efficacy of IGU therapy in patients with RA using ultrasonography (US)

Methods: Participants comprised 54 Japanese RA patients who had recently received IGU. All patients with a diagnosis of RA according to the 2010 ACR/EULAR criteria. Patients underwent clinical and laboratory assessments from baseline to 52 weeks, and US assessments at baseline, 12 and 24 weeks. Gray scale (GS) and power doppler (PD) signals were scored using a semiquantitative scale from 0 to 3 at $26(0-78)$ synovial sites (22 joints) in the following joints: bilateral first to fifth metacarpopharangeal (MCP) joints (dorsal recess); first interphalangeal (IP) and second to fifth proximal interphalangeal (PIP) (dorsal recess) joints; and the wrists (dorsal radial, median and ulnar).

Results: The patients included 16 males and 38 females. The mean age was $65.4 \pm 11.6$ years; the mean disease duration was $9.3 \pm 10.8$ years; and the number of MTX combination, other DMARD excluded combination, IGU monotherapy and Biologics combination were each $32,10,8$ and 4 cases.

Clinical findings related to RA were as follows: tender and swollen joint count, $4.2 \pm 2.9$ and $3.2 \pm 2.1$; patient's and physician's global assessment of disease activity, $40.2+24.0$ and $40.2 \pm 19.9 \mathrm{~mm}$; CRP, $1.0 \pm 1.2 \mathrm{mg} / \mathrm{dL}$; ESR, $31.2 \pm 18.2$ $\mathrm{mm} / \mathrm{h}$; DAS28-ESR, $4.37 \pm 0.88$ and SDAI, 16.4 \pm 7.0 . The mean DAS28-ESR improved to $3.43 \pm 0.94$ and $2.98 \pm 0.88$ at Week 12 and $24(p<0.001, p<0.001)$ and the mean SDAl improved to $8.8 \pm 6.1$ and $6.3 \pm 5.2$ at Week 12 and 24 $(p<0.001, p<0.001)$ significantly. The mean GS score changed from $16.8 \pm 12.5$ at baseline to $15.8 \pm 11.2(p=0.458)$ and $14.8 \pm 10.3(p=0.103)$ at week12 and 24. The mean PD score changed from $7.6 \pm 6.8$ at baseline to $5.8 \pm 6.0(p=0.053)$ and $5.3 \pm 5.4(p=0.05)$ at week12 and 24. In the achieved remission for DAS28-ESR at Week52 $(n=16)$ and not achieved or discontinued IGU patients $(n=38)$, the respective changes in GS and PD scores from baseline to 12 or 24 weeks were as follows: $\triangle$ GS score: $-3.7 \pm 0.8$ vs $0.1 \pm 6.8(p=0.068)$ at 12 weeks and $-5.8 \pm 5.7$ vs $-0.4 \pm 9.8(p=0.008)$ at 24 weeks; and $\triangle P D$ score: $-3.4 \pm 5.6$ vs $-1.1 \pm 5.2(p=0.065)$ at 12 weeks and $-4.9 \pm 6.3$ vs $-1.2 \pm 6.1(p=0.013)$ at 24 weeks (Fig.1). Areas under the receiver operating characteristic curves for the $\triangle \mathrm{GS}$ and $\triangle \mathrm{PD}$ score at each time point for remision achievement at 52 weeks were each 0.643 and 0.648 from week0 to 24 and 0.725 (cut-off index -3 , odds ratio 5.60 , sensitivity 0.74 , specificity, 0.67 ) and 0.706 (cut-off index -1 , odds ratio 4.71 , sensitivity 0.63 , specificity, 0.73) from week0 to 24 (Fig.2).
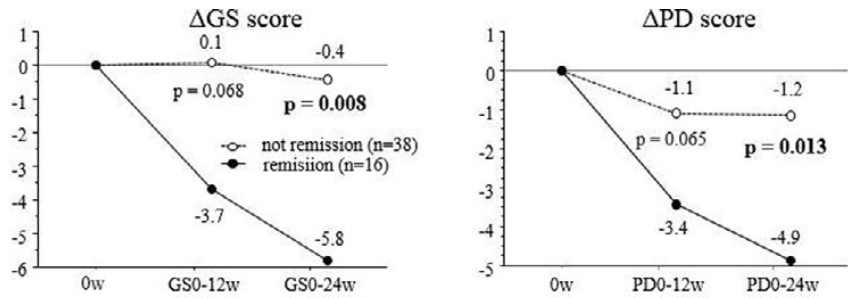

Figure 1: Respective changes in $\triangle \mathrm{GS}$ and $\triangle \mathrm{PD}$ score from baseline to Week 24

in the achieved remission for DAS28-ESR at Week52 and not achieved or discontinued IGU patients
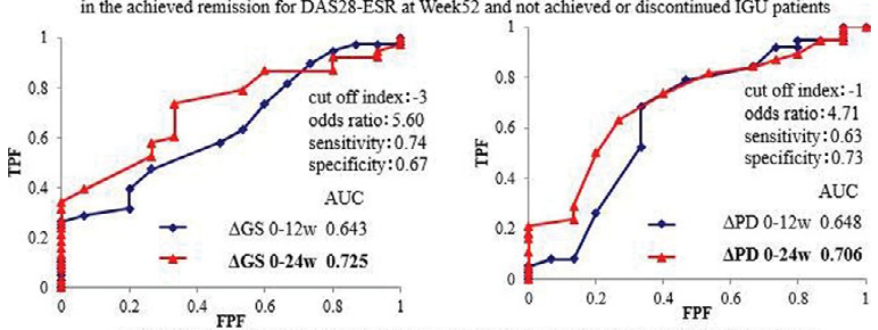

Figure $2: R O C$ curves of the $\triangle \mathrm{GS}$ and $\triangle \mathrm{PD}$ score at each time point from baseline to Week24 for predicting the achieved remission at Week 52 after starting IGU therapy 
Conclusions: The IGU therapy improved not only the disease activity not also the inflammatory synovitis. The present study provides evidence supporting the improvement of GS and PD score from baseline to week24 may predict whether the achieved remission or not at Week 52 .

Disclosure of Interest: None declared

DOI: 10.1136/annrheumdis-2017-eular.6948

\section{THU0213 COMPARATIVE EFFICACY AND SAFETY OF BARICITINIB 2 MG AND 4 MG IN PATIENTS WITH ACTIVE RHEUMATOID ARTHRITIS: A BAYESIAN NETWORK META-ANALYSIS OF RANDOMIZED CONTROLLED TRIALS}

Y.H. Lee, Y.H. Seo, G.G. Song. Rheumatology, Korea University Medicial Center, Seoul, Korea, Republic Of

Background: Baricitinib is a potent, selective JAK1 and JAK2 inhibitor. Baricitinib has been investigated in phase II and phase III studies of active patients with rheumatoid arthritis (RA). who showed an inadequate response to diseasemodifying antirheumatic drugs (DMARDs), including methotrexate (MTX) and biologics. However, due to the lack of adequate multiple comparisons, the comparative efficacy and safety of baricitinib in various treatment regimens with different dosages or in combination with DMARDs or MTX remains unclear. Objectives: This study aimed to assess the relative efficacy and safety of once-daily baricitinib $2 \mathrm{mg}$ and $4 \mathrm{mg}$ administration in patients with active RA. Methods: We performed a literature search using MEDLINE, EMBASE, the Cochrane Controlled Trials Register, and the EULAR and ACR conference proceedings. In this network meta-analysis, randomized controlled trials (RCTs) examining the efficacy and safety of baricitinib in patients with active RA were included. A Bayesian network meta-analysis was conducted to combine the direct and indirect evidence from the RCTs.

Results: Seven RCTs involving 3,461 patients met the inclusion criteria. There were 10 pairwise comparisons, including 7 direct comparisons and 5 interventions. The ACR20 response rate was significantly higher in the baricitinib $4 \mathrm{mg}$ in combination with disease-modifying antirheumatic drugs (DMARD) group than in the placebo+DMARD group (OR 3.13,95\% Crl 2.32-4.33). Compared with the placebo+DMARD group, the baricitinib $4 \mathrm{mg}$, baricitinib $2 \mathrm{mg}+\mathrm{DMARD}$, and adalimumab $40 \mathrm{mg}+\mathrm{MTX}$ groups showed a significantly higher ACR20 response rate. The ranking probability based on the surface under the cumulative ranking curve (SUCRA) indicated that baricitinib $4 \mathrm{mg}+\mathrm{DMARD}$ was likely to elicit the best ACR20 response rate (SUCRA $=0.7930$ ), followed by baricitinib $4 \mathrm{mg}$ (SUCRA $=0.7034)$, baricitinib $2 \mathrm{mg}+$ DMARD (SUCRA $=0.6304)$, adalimumab $40 \mathrm{mg}+\mathrm{MTX}$ (SUCRA $=0.3687$ ), and placebo+DMARD (SUCRA $=0.0045)$. By contrast, the safety based on the number of treatment-emergent adverse events (TEAEs) did not differ significantly among the 5 interventions.

Conclusions: Baricitinib $2 \mathrm{mg}$ and $4 \mathrm{mg}$ administered once daily was an efficacious intervention for active RA that had no significant risk of TEAE development.

Acknowledgements: None

Disclosure of Interest: None declared

DOI: 10.1136/annrheumdis-2017-eular.1245

\section{THU0214 LONG-TERM OUTCOME OF IGURATIMOD, CONVENTIONAL SYNTHETIC DISEASE-MODIFYNG ANTI-RHEUMATIC DRUD DEVELOPED IN JAPAN, IN JAPANESE PATIENTS WITH RHEUMATOID ARTHRITIS IN REAL-WORLD CLINICAL SETTING}

Y. Hirano, M. Isono, Y. Okada, Y. Oishi. Rheumatology, Toyohashi Municipal Hospital, Toyohashi, Japan

Background: Iguratimod (IGU) is csDMARDs developed in Japan and used in Japanese daily practice since 2012. Although IGU was developed as an anti-inflammatory drug at first, anti-rheumatic effect was found in experiments using type II collagen-induced arthritis model mice ${ }^{1)}$. Main mode of action of IGU was thought to be inhibition of NF-kB resulted in decreased production of IL-6, IL-8 and TNF-alpha ${ }^{2}$. Clinical trials performed in Japan showed that efficacy of IGU was equal to sulfasalazine when used as monotherapy in patients with rheumatoid arthritis (RA) ${ }^{3)}$. Additive efficacy to MTX was also shown in double-blind randomised trial in RA patients ${ }^{4}$ ). Although several short-term results were published ${ }^{5}$, long-term results in daily clinical setting is lacking.

Objectives: To investigate long-term outcome of IGU in patients with RA.

Methods: 120 RA patients treated with IGU in our institute from April 2013 to June 2016 were included. Patients' characteristics, factors influencing to prescribing of IGU (why was IGU chosen as treating csDMARDs?), drug continuation rates (Kaplan-Meier) were investigated. Time course of disease activity (DAS28-CRP \& SDAl) was also investigated using 65 cases who passed 2 years after starting of IGU.

Results: Baseline characteristics was as below. Mean age was 64.9 years old, \%female was $74.2 \%$, mean RA duration was 10.0 years and MTX was concomitant in $50.0 \%$ of cases. $82 \%$ of patients had factors influencing to prescribing IGU and intolerance of dose escalation of MTX was 1 st reason (23.3\%), old age over 80 years old was 2 nd reason (16.7\%) and economical reason was 3rd (14.2\%) (Table1). Drug continuation rates were $71.1 \%$ at 1 year, $48.9 \%$ at 2 years and
$43.1 \%$ at 3 years (Fig1). Time course of disease activity (baseline- 6 months-1 year-2 year) was 3.6-3.0-3.0-3.0 in DAS28-CRP. In 15 cases in remission of DAS28-CRP at 2 years, 2 were classified with high disease activity and 9 were moderate disease activity at baseline (Fig2).

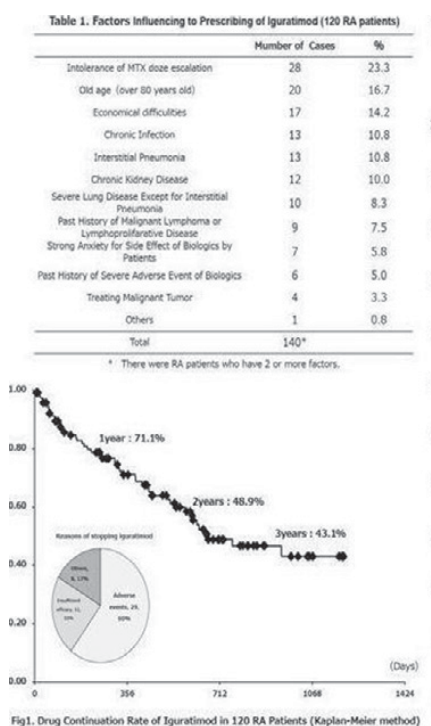

[DAS28-CRP Category (n=65) ] [SDAI Category (n=65)]

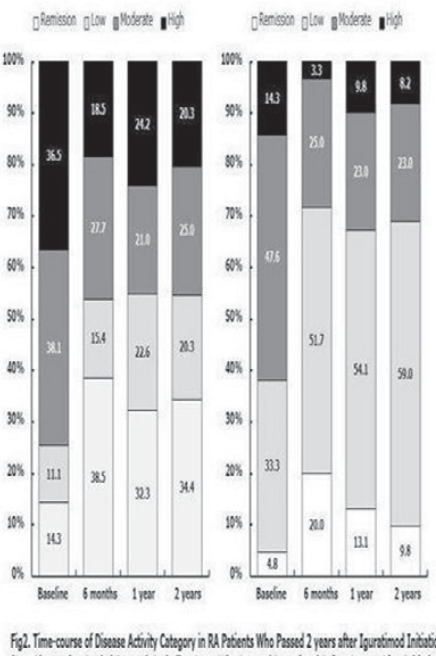

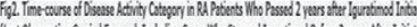

Conclusions: Efficacy of IGU in RA patients who had intolerance of MTX dose escalation or usage of biologics was observed. Although biological DMARDs is effective in RA patients, the cost is very expensive. IGU is comparative cheap ( $¥ 9,200 /$ month) and suitable for RA patients with economical difficulties. As IGU decreased TNF-alpha production via inhibition of NF-kB, MTX+IGU may have similar mode of action with MTX+TNF inhibitor. Drug continuation rates were decreased over time and escape of efficacy may occur in some patients. Otherwise, IGU was very effective in some cases. Some of RA patients with high disease activity decreased disease activity greatly to remission state at 2 years after initiation of IGU.

References:

[1] Aikawa et al. Inflamm res. 51; 188-194 2002.

[2] Kohno et al. J Rheumatol. 28; 2591-2596 2001.

[3] Hara et al. Mod Rheumatol. 17; 1-9 2007

[4] Ishiguro et al. Mod Rheumatol. 23; 430-439 2013.

[5] Yoshioka et al. Mod Rheumatol. 26; 169-174 2016.

Disclosure of Interest: None declared

DOI: 10.1136/annrheumdis-2017-eular.4852

\section{THU0215 EFFECTS OF TOFACITINIB ON PATIENT-REPORTED OUTCOMES IN A PHASE 3 STUDY OF CHINESE PATIENTS WITH ACTIVE RHEUMATOID ARTHRITIS AND AN INADEQUATE RESPONSE TO DMARDS}

Z. $\mathrm{Li}^{1}, \mathrm{Y} . \mathrm{An}{ }^{1}, \mathrm{G} . \mathrm{Li}^{2}, \mathrm{~L}$. Wang ${ }^{3}, \mathrm{~K} . \mathrm{Kwok}^{4}, \mathrm{Q}$. Wu ${ }^{2}$ on behalf of China ORAL group. ' 1 Peking University People's Hospital; ${ }^{2}$ Pfizer Inc, Beijing, China; ${ }^{3}$ Pfizer Inc, Groton, CT; ${ }^{4}$ Pfizer Inc, New York, NY, United States

Background: Rheumatoid arthritis (RA) worsens patients' health-related quality of life. ${ }^{1}$ Tofacitinib is an oral Janus kinase (JAK) inhibitor for the treatment of RA Improvements in patient-reported outcomes (PROs) have been reported in the global population of Phase 3 tofacitinib trials. ${ }^{2}$

Objectives: To explore the effect of tofacitinib administered with conventional synthetic DMARDs (csDMARDs) on PROs in Chinese patients with RA and an inadequate response to DMARDs.

Methods: This was a post-hoc analysis of data from Chinese patients in the 12 month, double-blind Phase 3 study ORAL Sync (NCT00856544), with patients randomised $4: 4: 1: 1$ to tofacitinib $5 \mathrm{mg}$ BID, tofacitinib $10 \mathrm{mg} \mathrm{BID}$, placebo (PBO) $\rightarrow$ tofacitinib $5 \mathrm{mg}$ BID or PBO $\rightarrow$ tofacitinib $10 \mathrm{mg}$ BID, with csDMARDs. Non-responders (defined as those who did not achieve a $20 \%$ improvement in both of the swollen or tender joint counts) receiving PBO advanced blindly to tofacitinib at Month 3; all remaining PBO patients advanced to tofacitinib at Month 6. Least squares mean changes from baseline were reported for Health Assessment Questionnaire-Disability Index (HAQ-DI), patient assessment of arthritis pain (VAS), patient global assessment of disease activity (PtGA), Functional Assessment of Chronic Illness Therapy (FACIT) Fatigue scale, Short Form-36 Health Survey (SF-36), EuroQol five dimensions questionnaire (EQ-5D), and Work Limitations Questionnaire (WLQ), using a mixed-effects model for repeated measures. All patients receiving $\geq 1$ dose of study treatment with $\geq 1$ post-baseline assessment were included.

Results: Overall 216 patients were included ( $n=86$, tofacitinib $5 \mathrm{mg} \mathrm{BID;} n=86$, tofacitinib $10 \mathrm{mg} \mathrm{BID} ; \mathrm{n}=22, \mathrm{PBO} \rightarrow$ tofacitinib $5 \mathrm{mg} \mathrm{BID} ; n=22, \mathrm{PBO} \rightarrow$ tofacitinib 